\title{
Erratum
}

\section{An Ecological Approach to Reducing Potentially Inappropriate Medication Use: Canadian Deprescribing Network-Erratum}

Cara Tannenbaum, Barbara Farrell, James Shaw, Steve Morgan, Johanna Trimble, Janet C. Currie, Justin Turner, Paula Rochon, and James Silvius

https:/ / doi.org/10.1017/S0714980816000702, published by Cambridge University Press, 16 January 2017

Due to a printer's error, Figures 1-4 on pages 98-100 of the article by Tannenbaum et al. (2017) in the March 2017 issue of Canadian Journal on Aging were printed in grayscale instead of color. The color versions of the figures follow below. We regret this error.

In addition, Janet C. Currie's name was incorrectly listed as Jane Currie. Her name has been corrected in the online version of the article.

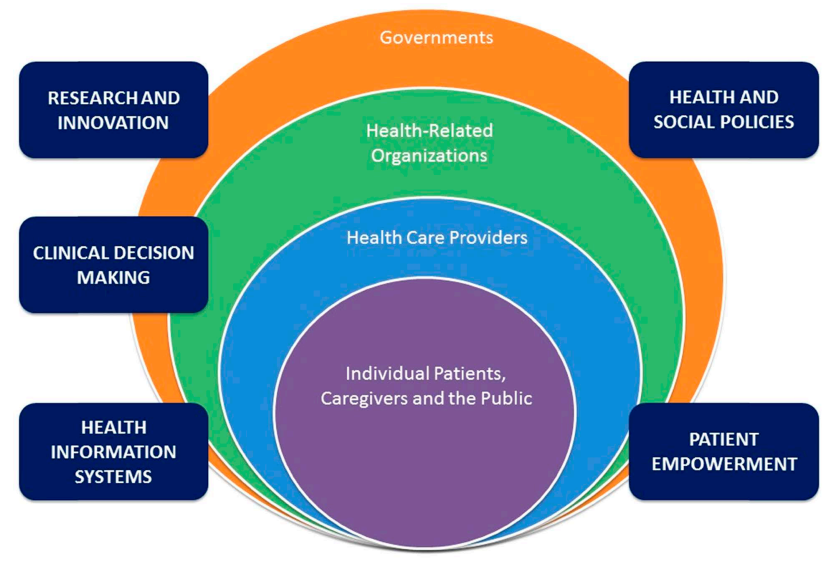

Figure 1: Ecological model of health system change.

Notes: Adapted from Richard et al. (2013). Interventions de prévention et promotion de la santé pour les aînés: modèle écologique. Guide d'aide à l'action francoquébécois. SaintDenis: Inpes, coll. Santé en action. 

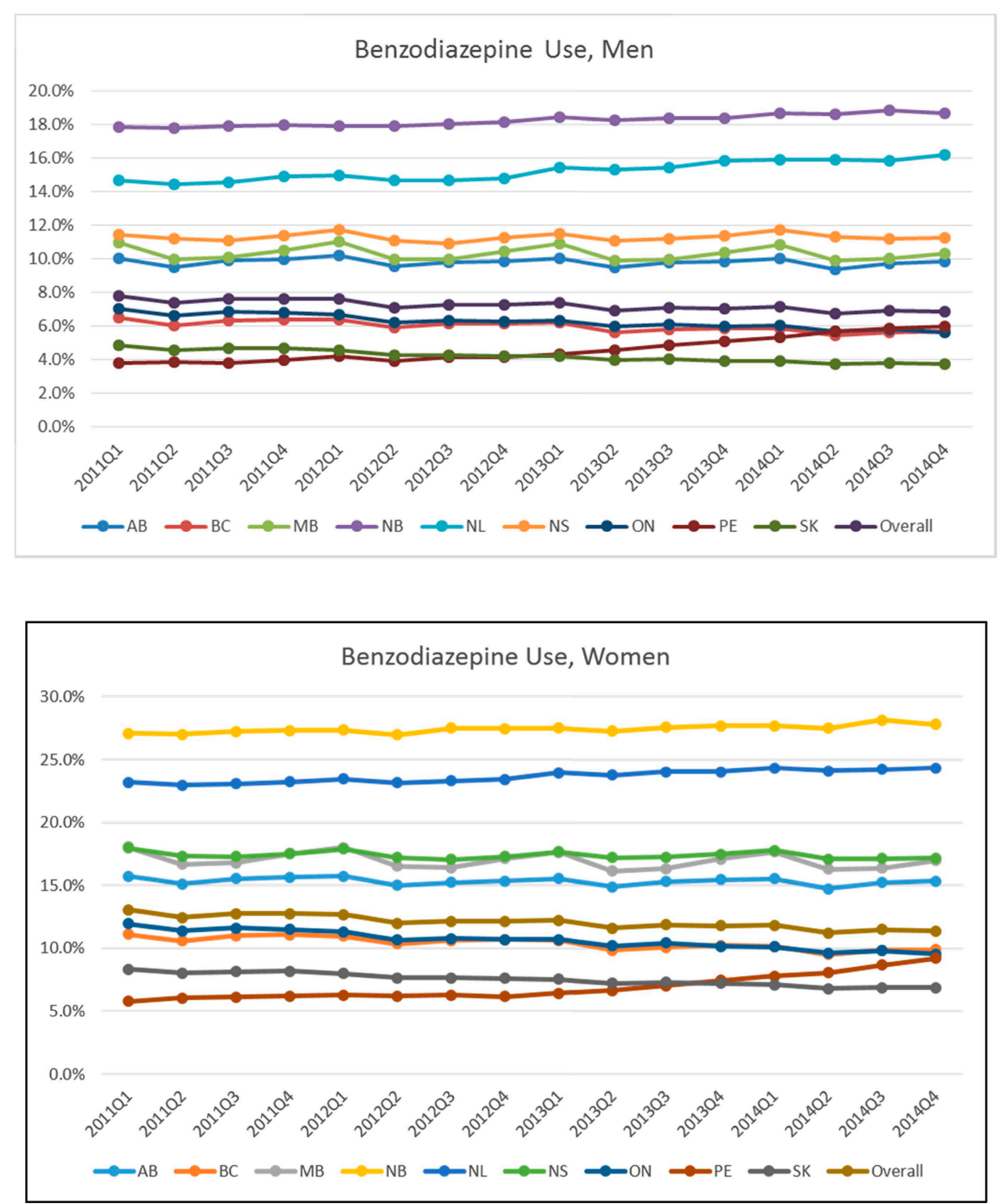

Figure 2: Proportion of community-dwelling men and women over the age of 65 with potentially inappropriate use of sedative hypnotics, selected provinces, 2011 to 2014.

\section{Notes:}

9 provinces submitting claims data to the NPDUIS Database as of December 2015: Newfoundland and Labrador, Prince Edward Island, Nova Scotia, New Brunswick, Ontario, Manitoba, Saskatchewan, Alberta, and British Columbia.

Q1, Q2, Q3, Q4 represent 4 consecutive 3-monthly periods (quarters) in each calendar year.

Source: National Prescription Drug Utilization Information System Database, Canadian Institute for Health Information. 

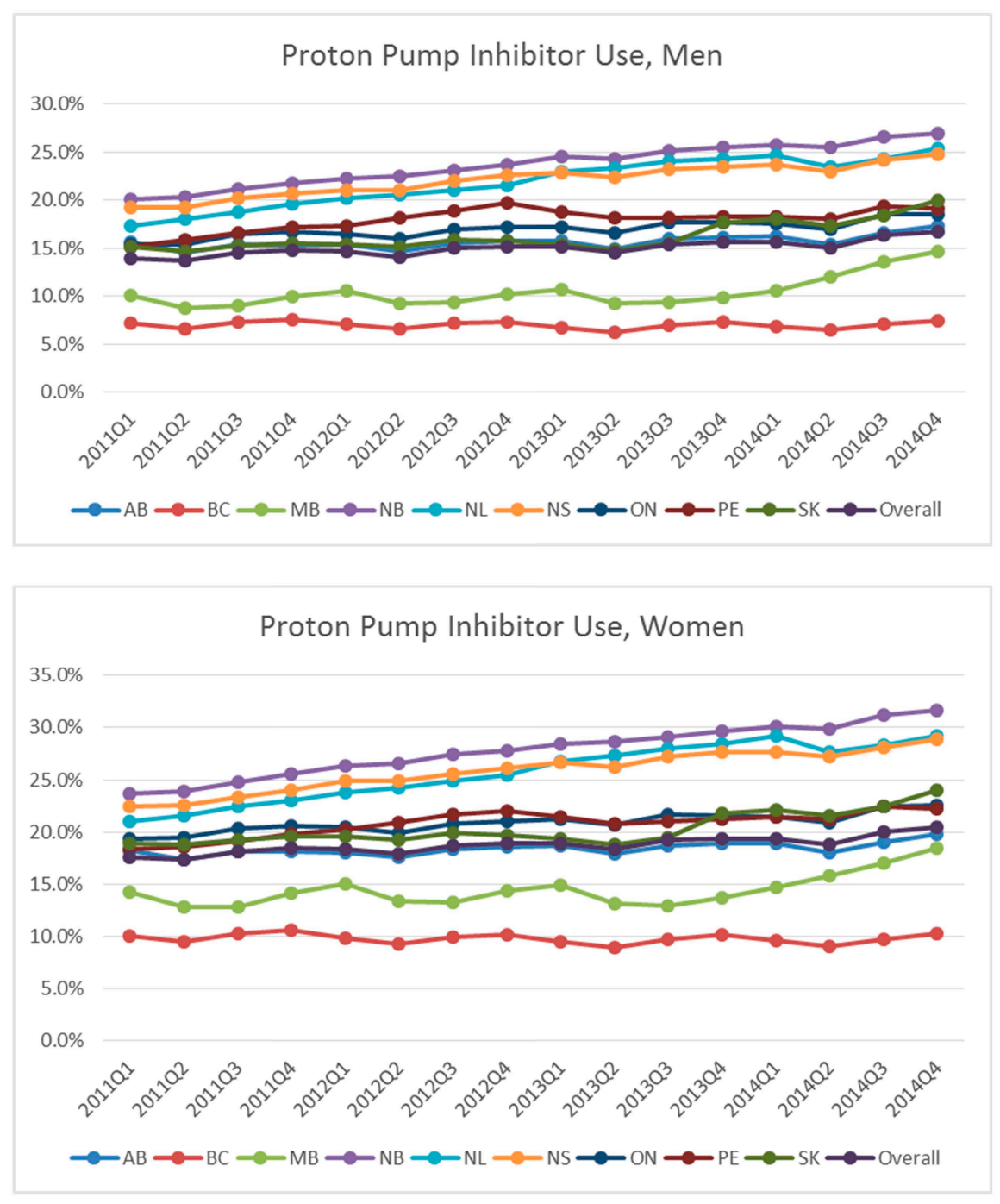

Figure 3: Proportion of community-dwelling men and women over the age of 65 with potentially inappropriate use of proton pump inhibitors, by province and quarter, selected provinces, 2011 to 2014.

Notes:

9 provinces submitting claims data to the NPDUIS Database as of December 2015: Newfoundland and Labrador, Prince Edward Island, Nova Scotia, New Brunswick, Ontario, Manitoba, Saskatchewan, Alberta, and British Columbia.

Q1, Q2, Q3, Q4 represent 4 consecutive 3-monthly periods (quarters) in each calendar year.

Source: National Prescription Drug Utilization Information System Database, Canadian Institute for Health Information. 

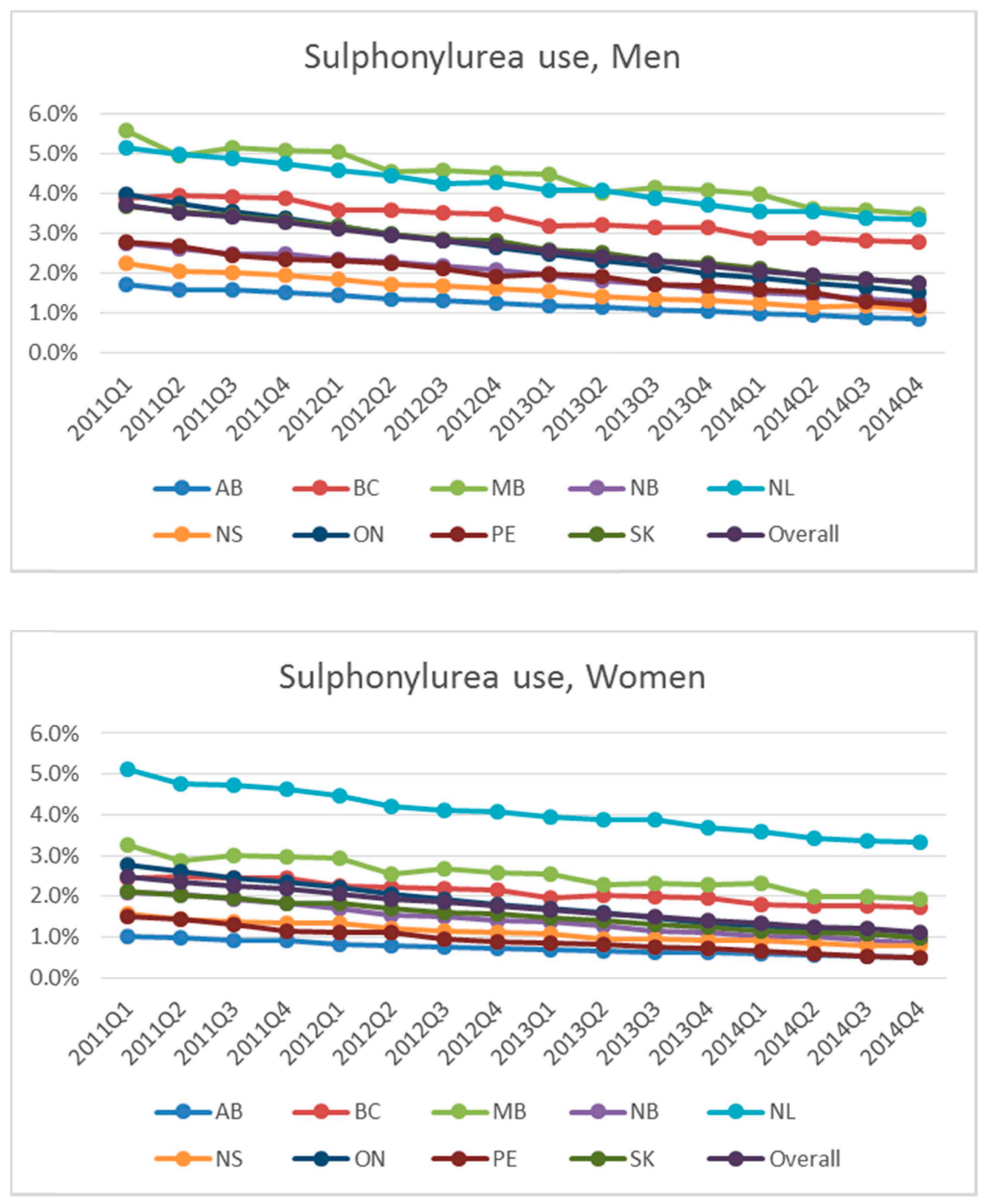

Figure 4: Proportion of community-dwelling men and women over the age of 65 with potentially inappropriate use of sulphonylurea drugs, by province and quarter, selected provinces, 2011 to 2014.

Notes:

9 provinces submitting claims data to the NPDUIS Database as of December 2015: Newfoundland and Labrador, Prince Edward Island, Nova Scotia, New Brunswick, Ontario, Manitoba, Saskatchewan, Alberta, and British Columbia.

Q1, Q2, Q3, Q4 represent 4 consecutive 3-monthly periods (quarters) in each calendar year.

Source: National Prescription Drug Utilization Information System Database, Canadian Institute for Health Information.

\section{Reference}

Tannenbaum, C., Farrell, B., Shaw, J., Morgan, S., Trimble, J., Currie, J. C., Turner, J., Rochon, P., \& Silvius, J. (2017). An ecological approach to reducing potentially inappropriate medication use: Canadian Deprescribing Network. Canadian Journal on Aging, 36(1), 97-107. https:/ /doi.org/10.1017/S0714980817000149. 